\title{
Examining the utility of the Hamilton early warning scores (HEWS) at triage: Retrospective pilot study in a Canadian emergency department
}

\author{
Steven Skitch, MD, $\mathrm{PhD}^{*}{ }^{\dagger}$; Benjamin Tam, BHSc, MD ${ }^{\dagger}$; Michael Xu, BHSc ${ }^{\ddagger}$; Laura Mclnnis, $\mathrm{BSc}^{\S}$; \\ Anthony $\mathrm{Vu}^{\S}$; Alison Fox-Robichaud, $\mathrm{MSc} \mathrm{MD}^{\dagger}$
}

\section{ABSTRACT}

Objectives: Early warning scores use vital signs to identify patients at risk of critical illness. The current study examines the Hamilton Early Warning Score (HEWS) at emergency department (ED) triage among patients who experienced a critical event during their hospitalization. HEWS was also evaluated as a predictor of sepsis.

Methods: The study population included admissions to two hospitals over a 6-month period. Cases experienced a critical event defined by unplanned intensive care unit admission, cardiopulmonary resuscitation, or death. Controls were randomly selected from the database in a 2-to-1 ratio to match cases on the burden of comorbid illness. Receiver operating characteristic (ROC) curves were used to evaluate HEWS as a predictor of the likelihood of critical deterioration and sepsis.

Results: The sample included 845 patients, of whom 270 experienced a critical event; 89 patients were excluded because of missing vitals. An ROC analysis indicated that HEWS at ED triage had poor discriminative ability for predicting the likelihood of experiencing a critical event 0.62 (95\% $\mathrm{Cl}$ 0.58-0.66). HEWS had a fair discriminative ability for meeting criteria for sepsis $0.77(95 \% \mathrm{Cl} 0.72-0.82)$ and good discriminative ability for predicting the occurrence of a critical event among septic patients 0.82 (95\% Cl 0.75-0.90).

Conclusion: This study indicates that HEWS at ED triage has limited utility for identifying patients at risk of experiencing a critical event. However, HEWS may allow earlier identification of septic patients. Prospective studies are needed to further delineate the utility of the HEWS to identify septic patients in the ED.

\section{RÉSUMÉ}

Objectifs: Les scores de détection précoce reposent sur les signes vitaux pour le repérage des patients susceptibles de souffrir d'une maladie grave. L'étude décrite ici portait sur le score de détection précoce Hamilton Early Warning Score
(HEWS), appliqué au moment du triage au service des urgences (SU) chez les patients ayant connu un événement grave durant leur hospitalisation. Le score HEWS a aussi fait l'objet d'évaluation comme indicateur prévisionnel de sepsie. Méthode: La population à l'étude se composait de malades admis dans deux hôpitaux, sur une période de six mois. Les " cas " étaient formés de malades ayant subi un événement grave, défini comme un séjour non prévu au service des soins intensifs, la réanimation cardiorespiratoire ou la mort. Les " témoins ", de leur côté, ont été choisis au hasard dans la base de données, et ce, dans un rapport de deux pour un afin d'apparier les cas selon le fardeau des maladies concomitantes. Enfin, les chercheurs se sont appuyés sur les courbes ROC (courbes caractéristiques de la performance d'un test) pour évaluer le score HEWS comme indicateur prévisionnel d'une détérioration grave et de sepsie.

Résultats: L'échantillon comptait 845 patients, dont 270 ont connu un événement grave. Quatre-vingt-neuf patients ont été écartés en raison de signes vitaux manquants. L'analyse ROC a indiqué que le score HEWS appliqué au moment du triage au SU avait une faible capacité de discrimination au regard des risques d'événements graves $(0,62$; [IC à $95 \%$ : $0,58-0,66])$, une capacité moyenne de discrimination au regard des critères de sepsie $(0,77$; [IC à $95 \%: 0,72-0,82])$ et une bonne capacité de discrimination au regard des risques d'événements graves chez les patients septicémiques $(0,82$; [IC à $95 \%: 0,75-0,90]$ ).

Conclusion: D'après les résultats de l'étude, le score HEWS appliqué au moment du triage au SU se révèle finalement peu utile dans le repérage des patients susceptibles de connaître un événement grave, bien qu'il puisse permettre la reconnaissance précoce des patients en état de septicémie. II faudrait mener des études prospectives afin de circonscrire davantage I'utilité du score HEWS dans le repérage des patients septicémiques au SU.

Keywords: emergency department, sepsis, triage, early warning scores

From the *Division of Emergency Medicine, †Division of Critical Care, $\neq$ Department of Health Research Methods, Evidence, and Impact, and $\S$ Michael G. DeGroote School of Medicine, McMaster University, Hamilton General Hospital, Hamilton, ON.

Correspondence to: Dr. Steven Skitch, Division of Emergency Medicine, McMaster University, Hamilton General Hospital, McMaster Clinic - 2nd Floor, 237 Barton Street East, Hamilton, ON L8L 2X2; Email: steven.skitch@medportal.ca 


\section{INTRODUCTION}

Early warning scores (EWSs) identify patients at risk of critical deterioration, as defined by the need for intensive care unit (ICU) admission, cardiopulmonary resuscitation, or death. There have been a variety of EWSs proposed, and they share common features. EWSs combine commonly measured physiological parameters, including heart rate, respiratory rate, temperature, blood pressure, oxygen saturation, and level of consciousness. The magnitude of derangement of each parameter from normal is used to generate a score indicating the patient's risk for deterioration. EWSs can predict risk of death and ICU admission among ward patients. ${ }^{1}$ Furthermore, combining an EWS with a rapid response team can improve survival and reduce cardiac arrest rates. ${ }^{2}$ Although developed for use in admitted patients, recent evidence suggests that EWSs may be useful in the emergency department (ED). ${ }^{3}$

Researchers have begun investigating the utility of an EWS calculated from triage vitals to predict the risk of subsequent patient deterioration. In a prospective observational cohort study, a higher EWS at triage predicted increased likelihood of requiring ICU admission and greater risk of in-hospital mortality. ${ }^{4,5} \mathrm{~A}$ recent study showed that an EWS using prehospital vitals also predicted similar outcomes. ${ }^{6}$ EWSs may be useful in the ED, but work is needed to determine how these scores may be optimally used. Earlier recognition of sepsis may be one benefit of using an EWS in the ED.

Sepsis is a common ED presentation and a major cause of morbidity and mortality in Canada. ${ }^{7}$ Sepsis recognition is time-sensitive because early identification and treatment are associated with improved outcomes. ${ }^{8}$
Unfortunately, sepsis is sometimes not identified at ED triage, ${ }^{9}$ and delayed identification is a potentially preventable cause of death. ${ }^{10}$ EWSs may help identify patients with occult sepsis. In a recent retrospective study conducted in a British ED, an EWS was able to identify patients at risk for septic shock with a $92 \%$ sensitivity and $77 \%$ specificity. ${ }^{11}$ Furthermore, among septic patients, a higher EWS at triage predicts an increased likelihood of ICU admission and 30-day mortality. ${ }^{12}$ These results suggest that the use of EWSs in the ED merits further research.

The Hamilton Early Warning Score (HEWS) is a novel EWS developed as part of a quality improvement and patient safety process at our centre. A committee consisting of physician leads, clinical managers, and rapid response team personnel conducted an extensive literature review of EWSs. The HEWS was developed based upon this review with modifications to existing scores based upon committee consensus. These modifications included a scoring trigger for delirium, gradation of the neurological score depending on the severity of depression in level of consciousness, and gradation in score depending on the amount of supplemental oxygen required. The details of the HEWS are provided in Table 1. In an initial study, the HEWS was found to be a significant predictor of critical inpatient events. Furthermore, the combination of HEWS and a rapid response team reduced the incidence of cardiac arrest and death. ${ }^{13}$

The current study is a retrospective review examining HEWS at ED triage as a predictor of the occurrence of critical events during admission. A secondary goal was to examine HEWS as a predictor of sepsis and the occurrence of critical events among septic patients. The most widely used and validated EWS is the

\begin{tabular}{|c|c|c|c|c|c|c|c|}
\hline Physiological parameters & 3 & 2 & 1 & 0 & 1 & 2 & 3 \\
\hline Heart rate & & $\leq 40$ & $41-50$ & $51-100$ & $101-110$ & $111-130$ & $>130$ \\
\hline Systolic blood pressure & $<71$ & $71-90$ & & $91-170$ & & $171-200$ & $>200$ \\
\hline Temperature & $\leq 35$ & & $35.1-36$ & $36.1-37.9$ & $38-39$ & $\geq 39.1$ & \\
\hline Respiratory rate & $<8$ & $8-13$ & & $14-20$ & & $21-30$ & $>30$ \\
\hline Oxygen saturation & $<85$ & & $85-92$ & $>92$ & & & \\
\hline Supplemental oxygen & & & & Room air & $\leq 5 \mathrm{~L} / \mathrm{min}$ or $<50 \%$ & & $\begin{array}{c}>5 \mathrm{~L} / \mathrm{min} \text { or } \\
\geq 50 \%\end{array}$ \\
\hline CNS change from baseline ${ }^{a}$ & & $\mathrm{CAM}+\mathrm{ve}$ & & $A$ & V & $P$ & U \\
\hline
\end{tabular}




\begin{tabular}{|c|c|c|c|c|c|c|c|}
\hline Physiological parameters & 3 & 2 & 1 & 0 & 1 & 2 & 3 \\
\hline Heart rate & $\leq 40$ & & $41-50$ & $51-90$ & $911-110$ & $111-130$ & $>130$ \\
\hline Systolic blood pressure & $\leq 90$ & $91-100$ & $101-110$ & $111-219$ & & & $\geq 220$ \\
\hline Temperature & $\leq 35$ & & $35.1-36$ & $36.1-38$ & $38.1-39$ & $\geq 39.1$ & \\
\hline Respiratory rate & $\leq 8$ & & $9-11$ & $12-20$ & & $21-24$ & $\geq 25$ \\
\hline Oxygen saturation & $\leq 91$ & $92-93$ & $94-95$ & $\geq 96$ & & & \\
\hline Supplemental oxygen & & Yes & & No & & & \\
\hline Level of consciousness & & & & A & & & $V, P, U$ \\
\hline
\end{tabular}

National Early Warning Score (NEWS), which is used within the British National Health Service. ${ }^{1}$ The details of the NEWS are described in Table 2. For comparative purposes, NEWS at triage was also calculated and analysed as a predictor of outcomes.

\section{METHODS}

\section{Study setting}

Approval was obtained from our local research ethics boards. This study was conducted at two academic, tertiary care, adult hospitals affiliated with Hamilton Health Sciences with a combined total annual ED census of 86,000 . This study is a secondary analysis of a larger prospectively identified database of consecutive patients admitted to medical and surgical floors during the 6-month implementation of HEWS on the wards, which began in January $2014 .{ }^{13,14}$ The current study included only patients who were admitted through the ED.

\section{Data collection methods}

Data were collected using techniques recommended for ED medical record reviews. ${ }^{15}$ Two investigators (LM and AV) were trained to abstract data from medical charts. These investigators were blinded to the study purpose during the period of data abstraction. A standardized protocol with pre-specified variables definitions was created for data abstraction. Data were entered into an electronic spreadsheet created using Microsoft Access 2010 (Microsoft Corp., Redmond, WA). A random sample of $10 \%$ of records was reviewed by a second abstractor to allow calculation of interrater agreement using the kappa statistic ( $\kappa)$. Disagreements or uncertainties in coding were resolved by consensus between the data abstractors and the senior resident principal investigator (SS). In all cases, the faculty principal investigator (AFR) was available to review any cases where consensus could not be reached.

\section{Identification of cases and controls}

Charts were reviewed for a critical event identified as an in-hospital death, cardiac arrest, or ICU transfer. Cardiac arrest included pulseless ventricular tachycardia, ventricular fibrillation, pulseless electrical activity/ asystole, or respiratory arrests. ICU transfers were specifically unexpected ICU transfers and excluded patients who were admitted directly to the ICU from the ED or transferred to the ICU for postoperative monitoring. Cases were patients who experienced a critical event during their hospitalization. A cohort of patients who did not experience a critical event were selected as controls. Controls were selected randomly to match cases in a two-to-one fashion. To match cases and controls in terms of severity of comorbid illness, the Charlson Comorbidity Index (CCI) was used. The CCI is designed to predict a patient's 1-year mortality based upon his or her burden of comorbid disease and is commonly in health records research. ${ }^{16}$ A CCI score was calculated for each patient based upon review of his or her electronic medical record. A random selection of controls was weighted to match cases on the patients' CCI scores to ensure a similar baseline burden of disease in the groups.

\section{Abstraction of emergency department data}

Demographic variables were abstracted, including age, gender, mode of ED arrival, and Canadian Triage and 
Acuity Scale (CTAS) level. HEWS was calculated based upon triage vitals. A standardized process was used to score neurological status based on nursing documentation of level of consciousness or the presence of delirium. HEWS was documented as missing if neurological assessment could not be interpreted or if any of the vital signs were incomplete. The presence of the systemic inflammatory response syndrome (SIRS) was determined based upon initial triage vitals and ED blood work using the American College of Chest Physicians - Society of Critical Care Medicine criteria for SIRS. ${ }^{17}$ The presence of an infection-related diagnoses was determined based upon recorded admission diagnosis using diagnostic codes from the Acute Physiology and Chronic Health Evaluation (APACHE) III prognostic system. A similar technique has been used in contemporary sepsis studies. ${ }^{18}$ Patients who met SIRS criteria and were admitted with an infection-related diagnoses were considered septic.

\section{Data analysis}

Analyses were performed using SPSS Statistics Version 23 (IBM, Chicago, IL) and were conducted by study investigators (SS and MX) with graduate-level training in statistics. Differences between cases and controls were examined using t-tests for continuous variables and a chi-square test analysis for categorical variable. The primary outcome of interest was the ability of HEWS at triage to predict patients who experienced a critical event during their admission. This was evaluated by plotting the sensitivity (true positives) against one-specificity (false positives) using receiver operating characteristic (ROC) curves and calculating the area under the curve (AUC) to evaluate the overall performance of HEWS. Sensitivity, specificity, positive likelihood ratios, and negative likelihood ratios for various HEWS cut-offs were also calculated. In line with cut-offs used with admitted ward patients, comparisons were made across three groups of patients: moderate-risk (HEWS $\geq 3$ ), high-risk $(\mathrm{HEWS} \geq 6)$, and very high-risk $(\mathrm{HEWS} \geq 9) .{ }^{14}$ A secondary study goal was to examine HEWS as a predictor of sepsis. As such, a similar ROC curve analysis was performed to examine HEWS as a predictor of meeting criteria for sepsis among both the total sample and among only the patients who experienced a critical event during their admission. Finally, ROC curves were calculated using NEWS to provide a comparison of the HEWS with a previously validated score.

\section{RESULTS}

\section{Patient characteristics}

The flow of patients in the final sample is summarized in Figure 1. Patients totalling 845 were included in the final sample, including 270 cases who experienced a critical event. These index critical events included 23 inpatient arrests (9\%), 95 unplanned ICU transfers (36\%), and 149 deaths (56\%); 89 patients had missing triage vitals and could not have a HEWS calculated. Missing vital signs included fever (72\%), oxygen saturation (12\%), respiratory rate $(3 \%)$, neurological status $(1 \%)$, blood pressure $(1 \%)$, and $10 \%$ missing multiple vital signs. Cases $(\mathrm{n}=35)$ were no more likely than controls $(\mathrm{n}=54)$ to have missing triage vital $\left(\chi^{2}(1)=2.49, p=0.12\right)$. The remaining analysis included only patients with complete triage vitals in whom a HEWS could be determined. Table 3 presents the demographic characteristics for cases and controls. Cases were significantly more likely to be male, to arrive by ambulance, to have an infectionrelated diagnoses, to be SIRS positive, and to be classified as septic.

\section{Interrater agreement}

Interrater agreement was very good for most variables, including: 1) triage HEWS 0.89 ; 2) presence of SIRS criteria $1.00 ; 3)$ presence of an infection-related diagnoses 0.85 ; and 4) occurrence of a critical event 0.89. Agreement was good for the determination of a CCI score with a kappa of 0.64 .

\section{ROC curve analysis}

The ROC curve for HEWS at triage as a predictor of the primary outcome, occurrence of a critical event during admission, is illustrated in Figure 2. The AUC for HEWS to predict the occurrence of a critical event during admission is 0.62 (95\% confidence interval [CI] 0.58-0.66). Table 4 presents diagnostic test characteristics of various pre-specified HEWS cut-offs for predicting the likelihood of experiencing a critical event. The ROC curves for HEWS as a predictor of the secondary outcomes, meeting criteria for sepsis, and the occurrence of a critical event among septic patients are presented in Figures 3 and 4, respectively. The AUC for HEWS to predict the likelihood of sepsis is 0.77 (95\% CI 0.72-0.82), and among the cases the AUC is 


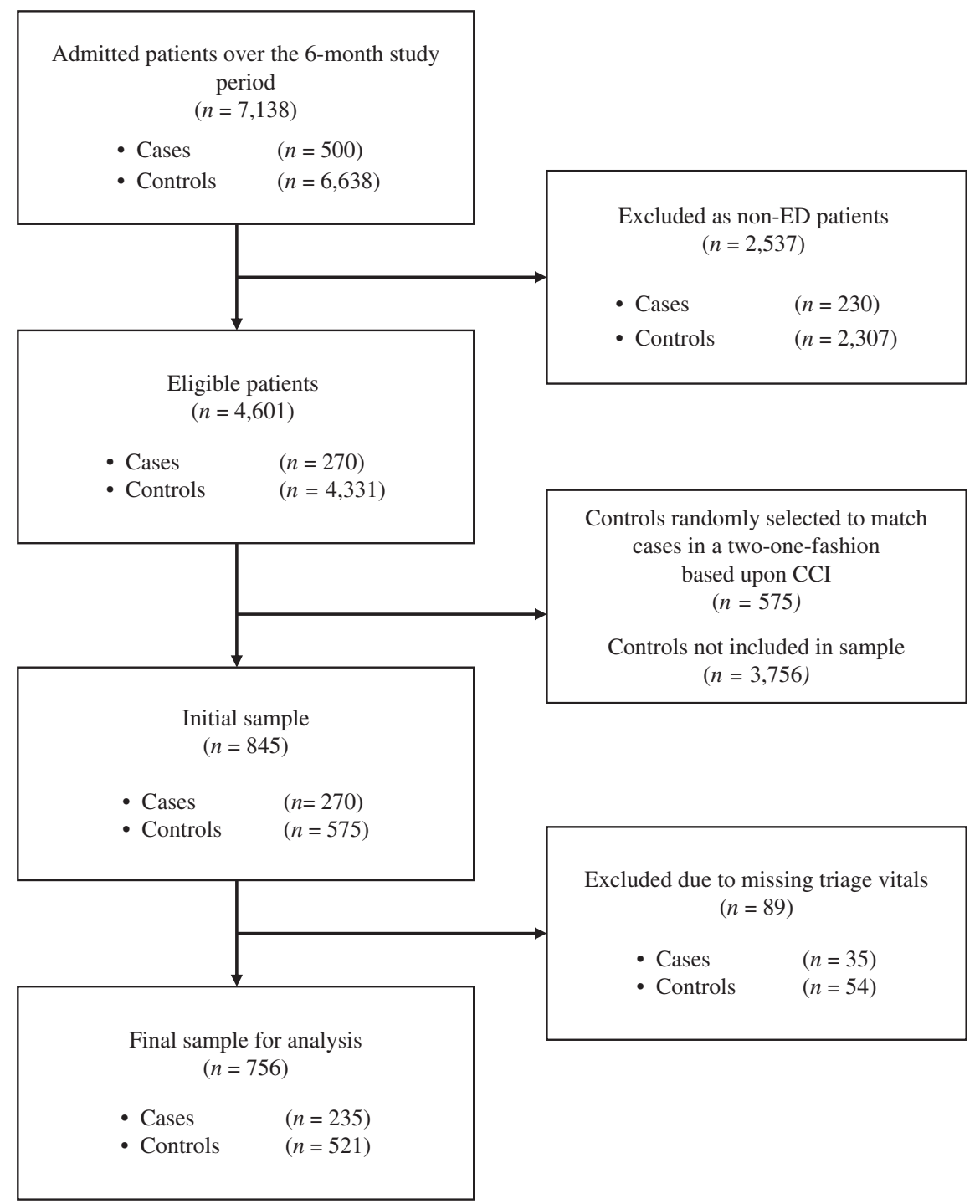

Figure 1. Flow diagram of included and excluded participants. $\mathrm{CCl}=$ Charlson Comorbidity Index.

\begin{tabular}{|c|c|c|c|}
\hline Variable & $\begin{array}{c}\text { Cases } \\
(n=235)\end{array}$ & $\begin{array}{l}\text { Controls } \\
(n=521)\end{array}$ & $p$ value \\
\hline Age & $76.7 \pm 13.7$ & $75.4 \pm 13.7$ & 0.24 \\
\hline Male (n [\%]) & $130(55 \%)$ & $240(46 \%)$ & $0.03 *$ \\
\hline Charlson Comorbidity Index & $7.7 \pm 3.1$ & $7.5 \pm 3.2$ & 0.27 \\
\hline Arrival by ambulance (n [\%]) & 175 (74\%) & $347(67 \%)$ & $0.03^{*}$ \\
\hline CTAS 1 or 2 (n [\%]) & $104(44 \%)$ & 205 (39\%) & 0.12 \\
\hline Infection diagnoses & $85(36 \%)$ & $114(22 \%)$ & $0.01 *$ \\
\hline SIRS positive & $105(47 \%)$ & $150(27 \%)$ & $0.01 *$ \\
\hline Septic & $50(21 \%)$ & $59(11 \%)$ & $0.01^{*}$ \\
\hline
\end{tabular}

0.82 (95\% CI $0.75-0.90)$. Table 5 presents diagnostic test characteristics of HEWS at predicting the sepsisrelated outcomes.
Additional exploratory analyses were conducted to examine the utility of HEWS in identifying septic patients who were assigned an initial CTAS level of III or lower. This cut-off was selected because experts have recommended that septic patients should be assigned a minimum CTAS level of $I I .^{19}$ In our sample, 47 patients meeting sepsis criteria were assigned a CTAS level of III or IV. The mean HEWS score for these patients was $2.8(\mathrm{SD}=2.1)$, which was significantly greater than non-septic CTAS III or IV patients $(M=1.4, \mathrm{SD}=1.7), t(433)=5.3, p<0.01$.

\section{National Early Warning Score}

The ROC curve for NEWS as a predictor of the occurrence of a critical event is illustrated in Figure 2. 


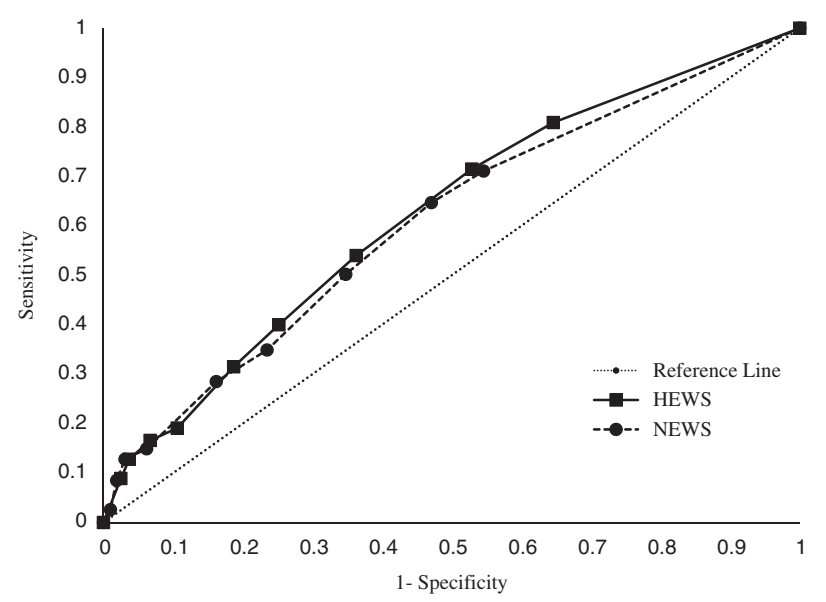

Figure 2. ROC curve for HEWS at triage and NEWS at triage as a predictor of the occurrence of a critical event during admission as defined by the combination of arrest, unplanned ICU transfer, or death.

HEWS = Hamilton Early Warning Score; NEWS = National Early Warning Score.

\begin{tabular}{|c|c|c|c|c|}
\hline HEWS $\geq$ & $\begin{array}{l}\text { Sensitivity \% } \\
(95 \% \mathrm{Cl})\end{array}$ & $\begin{array}{c}\text { Specificity \% } \\
(95 \% \text { Cl) }\end{array}$ & $\begin{array}{c}+\mathrm{LR} \\
(95 \% \mathrm{Cl})\end{array}$ & $\begin{array}{c}-\mathrm{LR} \\
(95 \% \mathrm{Cl})\end{array}$ \\
\hline 3 & $\begin{array}{c}54 \\
(47-61)\end{array}$ & $\begin{array}{c}63 \\
(59-68)\end{array}$ & $\begin{array}{c}1.49 \\
(1.26-1.75)\end{array}$ & $\begin{array}{c}0.72 \\
(0.62-0.84)\end{array}$ \\
\hline 6 & $\begin{array}{c}19 \\
(15-25)\end{array}$ & $\begin{array}{c}89 \\
(87-92)\end{array}$ & $\begin{array}{c}1.84 \\
(1.28-2.65)\end{array}$ & $\begin{array}{c}0.90 \\
(0.84-0.97)\end{array}$ \\
\hline 9 & $\begin{array}{c}9 \\
(6-13)\end{array}$ & $\begin{array}{c}98 \\
(96-99)\end{array}$ & $\begin{array}{c}3.57 \\
(1.82-7.02)\end{array}$ & $\begin{array}{c}0.93 \\
(0.90-0.97)\end{array}$ \\
\hline
\end{tabular}

The AUC for NEWS to predict the occurrence of a critical event during admission is 0.61 (95\% CI 0.57 0.65). ROC curves for NEWS as a predictor of the secondary outcomes, meeting criteria for sepsis and the occurrence of a critical event among septic patients, is presented in Figures 3 and 4, respectively. The AUC for NEWS to predict likelihood of sepsis is 0.73 (95\% CI 0.67-0.79), and among cases the AUC is 0.79 (95\% CI 0.72-0.85). Comparing the ROC curves for the HEWS and NEWS shows that $95 \%$ CI of the AUC overlaps for each outcome studied.

\section{DISCUSSION}

This study is the first evaluation of an EWS at triage in a Canadian ED. The use of a retrospective cohort of admitted patients allowed the inclusion of a relatively large number of patients who experienced a critical event

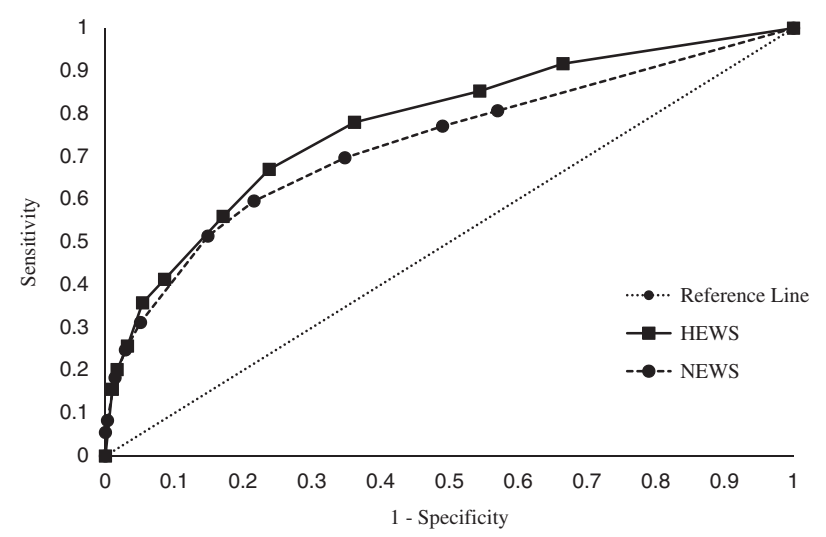

Figure 3. ROC curve for HEWS at triage and NEWS at triage as a predictor of the occurrence of a sepsis in the total sample.

HEWS = Hamilton Early Warning Score; NEWS = National Early Warning Score.

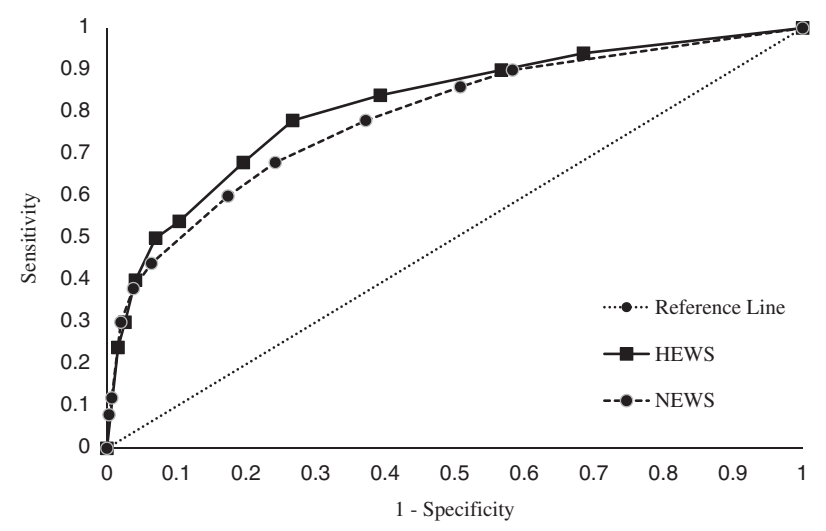

Figure 4. ROC curve for HEWS at triage and NEWS at triage as a predictor of the occurrence of a sepsis among patient experiencing a critical event.

HEWS = Hamilton Early Warning Score; NEWS = National Early Warning Score.

in comparison with previous studies examining EWSs in the ED. ${ }^{4-6}$ ROC analysis indicates that, although HEWS at triage is a statistically significant predictor of the likelihood of experiencing a critical event among admitted patients, it lacks sufficient discriminative power to be clinically useful for this outcome. Further discussion on ROC interpretation ${ }^{20}$ is available. The occurrence of critical events was chosen as the primary outcome because it has been evaluated in previous studies of EWSs among ward and ED patients. ${ }^{1-6}$ However, this outcome may not be ideal to evaluate the utility of an EWS in the ED. Many additional variables beyond initial physiological derangement at ED presentation are likely to impact upon risk for the 


\begin{tabular}{|c|c|c|c|c|}
\hline HEWS $\geq$ & $\begin{array}{l}\text { Sensitivity \% } \\
\quad(95 \% \mathrm{Cl})\end{array}$ & $\begin{array}{l}\text { Specificity \% } \\
\text { (95\% Cl) }\end{array}$ & $\begin{array}{c}+\mathrm{LR} \\
(95 \% \mathrm{Cl})\end{array}$ & $\begin{array}{c}-\mathrm{LR} \\
(95 \% \mathrm{Cl})\end{array}$ \\
\hline \multicolumn{5}{|l|}{ Sepsis } \\
\hline \multirow[t]{2}{*}{3} & 78 & 64 & 2.15 & 0.35 \\
\hline & (69-86) & $(60-68)$ & $(1.87-2.49)$ & $(0.24-0.49)$ \\
\hline \multirow[t]{2}{*}{6} & 41 & 91 & 4.82 & 0.64 \\
\hline & $(32-51)$ & (89-94) & $(3.43-6.76)$ & $(0.55-0.75)$ \\
\hline \multirow[t]{2}{*}{9} & 20 & 98 & 11.56 & 0.81 \\
\hline & $(13-29)$ & (97-99) & $(5.77-23.15)$ & $(0.74-0.89)$ \\
\hline \multicolumn{5}{|c|}{ Sepsis and critical event } \\
\hline \multirow[t]{2}{*}{3} & 84 & 61 & 2.14 & 0.26 \\
\hline & (71-93) & $(59-68)$ & $(1.83-2.49)$ & $(0.14-0.50)$ \\
\hline \multirow[t]{2}{*}{6} & 54 & 90 & 5.17 & 0.51 \\
\hline & (39-68) & $(87-92)$ & (3.69-7.23) & $(0.38-0.69)$ \\
\hline \multirow[t]{2}{*}{9} & 30 & 97 & 11.48 & 0.72 \\
\hline & $(18-45)$ & (96-98) & $(6.16-21.39)$ & $(0.60-0.86)$ \\
\hline
\end{tabular}

occurrence of a critical event during admission. Future ED EWS studies should focus on outcomes more likely to be related to ED presentation such as early unplanned ICU admission, mortality, and the development of new organ dysfunction.

A comparison of the HEWS with the NEWS reveals that the performance of the scores was not significantly different in our sample. The two scores evaluate similar variables but differ in their relative weighting and scoring. In particular, the two scores differ in their evaluation of mental status alterations. The NEWS uses the alert-voice-pain-unresponsive (AVPU) scale with any alteration in level of consciousness receiving a maximum score. In contrast, the HEWS scores the AVPU scale in gradated fashion and assesses for the presence of delirium using the confusion assessment method (CAM). In our study, the neurological component of each score was retrospectively calculated based upon triage nurse documentation. As such, we cannot assess the relative ease of using each score in the ED. Prospective research is needed to assess if delirium and level of consciousness can be effectively assessed during a brief triage assessment. Previous research has demonstrated that the nurses can successfully apply the CAM to identify delirious ED patients. ${ }^{21}$ Future studies should be conducted to determine the optimal methods of deriving and validating the components of EWSs that maximize their predicative ability in a given clinical environment. $^{22}$
In line with previous research, HEWS at ED triage was useful as a predictor of sepsis and the occurrence of critical events among septic patients. This is notable because septic patients can deteriorate if they do not receive early recognition and treatment. ${ }^{23}$ HEWS may be a useful adjunct to triage systems such as the CTAS by identifying potentially septic patients within a CTAS level who need to be seen more urgently. In our sample, septic patients assigned a CTAS level of III or IV had a higher HEWS score than non-septic patients with a similar CTAS level. An elevated HEWS could also be used to trigger a medical directive for triage nurse initiated bloodwork to detect markers of organ dysfunction such as elevated lactate and creatinine. Before implementation of such a proposal, prospective studies examining the diagnostic test characteristics of the HEWS among an unselected sample of ED patients are needed. The ROC values for HEWS in our sample may not generalize to all ED patients, given that our sample included admitted patients only. Such a study is needed to determine whether the additional costs of screening and testing using HEWS are justified by the number of cases detected. ${ }^{24}$

The definition of sepsis and the optimal method of identifying septic patients is an active area of research. Novel sepsis definitions were recently published that include a proposed bedside clinical score to identify septic patients in the ED setting who are at increased risk of in-hospital mortality. ${ }^{25}$ This measure, called 
qSOFA, is positive if patients have at least two of the following clinical criteria: altered mentation as defined by a Glasgow coma scale score of $<15$, a respiratory rate of 22 breaths per minute or greater, or a systolic blood pressure of $100 \mathrm{~mm} \mathrm{Hg}$ or less. Research is needed to examine the utility of qSOFA in comparison to measures such as HEWS. Such research would be valuable, given that EWSs are currently used as part of patient monitoring in many wards and EDs.

\section{LIMITATIONS}

The current study has several limitations. First, this was a retrospective study using clinical data not originally collected for this research purpose. We attempted to maximize the reliability of our data abstraction using recommended strategies to improve methodological quality. ${ }^{15}$ Future studies should prospectively record HEWS to improve the validity of recorded data and examine relevant variables such as time from ED admission to the occurrence of critical events. Second, our sample was restricted to patients admitted to hospital wards through the ED. Future research is needed to determine whether the results generalize to all ED patients. Third, our study was conducted within a single hospital system, at two tertiary academic centres. It is unclear whether our results would generalize to other types of centres. Fourth, HEWS cut-offs were based upon those used for ward patients. Future research is needed to evaluate optimal HEWS cut-off levels among ED patients. Fifth, 89 patients (10.5\%) had missing triage vital signs and were excluded from analysis. The most common missing vital sign was fever, which is likely to be important in the early detection of infection-related diagnoses. Previous research has documented even higher rates of missing vital signs at ED triage. ${ }^{26}$ Implementation of an EWS at triage may improve the consistency of vital sign documentation, and this should be evaluated in future studies.

\section{CONCLUSIONS}

The HEWS has potential utility in the ED to allow earlier identification of patients with sepsis. Future research is needed to determine whether the HEWS can be incorporated as part of existing triage systems and used to implement earlier screening and intervention and thereby prevent deterioration of these patients. Investigators should also incorporate qualitative research methods to determine whether hospital-wide adoption of an EWS such as HEWS improves continuity of care for critically ill patients.

Acknowledgements: The authors thank the dedicated staff of Hamilton Health Sciences Decision Support Services who assisted with case identification for database creation.

Financial support: This project received funding from the Hamilton Health Sciences Resident Research Grant in Patient Safety as well as the Hamilton Health Sciences Department Quality and Patient Safety Award awarded to Benjamin Tam. Funding parties were not involved in the design of the study.

Competing interests: None declared.

\section{REFERENCES}

1. Smith GB, Prytherch DR, Meredith P, et al. The ability of the National Early Warning Score (NEWS) to discriminate patients at risk of early cardiac arrest, unanticipated intensive care unit admission, and death. Resuscitation 2013;84(4):465-70.

2. McNeill G, Bryden D. Do either early warning systems or emergency response teams improve hospital patient survival? A systematic review. Resuscitation 2013;84(12):1652-67.

3. Brabrand M, Folkestad L, Clausen NG, et al. Risk scoring systems for adults admitted to the emergency department: a systematic review. Scand 7 Trauma Resusc Emerg Med 2010;18:8.

4. Alam N, Vegting IL, Houben E, et al. Exploring the performance of the National Early Warning Score (NEWS) in a European emergency department. Resuscitation 2015;90:111-5.

5. Groarke JD, Gallagher J, Stack J, et al. Use of an admission early warning score to predict patient morbidity and mortality and treatment success. Emerg Med 7 2008;25(12):803-6.

6. Silcock DJ, Corfield AR, Gowens PA, et al. Validation of the National Early Warning Score in the prehospital setting. Resuscitation 2015;89:31-5.

7. Martin CM, Priestap F, Fisher H, et al. A prospective, observational registry of patients with severe sepsis: the Canadian Sepsis Treatment and Response Registry. Crit Care Med 2009;37(1):81-8.

8. Gaieski DF, Mikkelsen ME, Band RA, et al. Impact of time to antibiotics on survival in patients with severe sepsis or septic shock in whom early goal-directed therapy was initiated in the emergency department. Crit Care Med 2010;38(4):1045-53.

9. Chamberlain DJ, Willis E, Clark R, et al. Identification of the severe sepsis patient at triage: a prospective analysis of the Australasian Triage Scale. Emerg Med f 2015;32(9):690-7.

10. Goulet H, Guerand V, Bloom B, et al. Unexpected death within 72 hours of emergency department visit: were those deaths preventable? Crit Care 2015;19(1):1-7.

11. Keep J, Messmer A, Sladden R, et al. National early warning score at emergency department triage may allow earlier identification of patients with severe sepsis and septic shock: a retrospective observational study. Emerg Med 2016;33(1):37-41. 
12. Corfield AR, Lees F, Zealley I, et al. Utility of a single early warning score in patients with sepsis in the emergency department. Emerg Med 7 2014;31(6):482-7.

13. Tam B, Xu M, Fox-Robichaud A. Hamilton Early Warning Score: predict, prevent and protect. Crit Care 2015;19(Suppl 1): P501.

14. Tam B, Fox-Robichaud A. Using a stratified Hamilton Early Warning Score (HEWS) at admission to predict critical events and workload. Toronto, ON: Critical Care Canada Forum; 2015.

15. Worster A, Bledsoe RD, Cleve P, et al. Reassessing the methods of medical record review studies in emergency medicine research. Ann Emerg Med 2005;45(4):448-51.

16. Needham DM, Scales DC, Laupacis A, et al. A systematic review of the Charlson Comorbidity Index using Canadian administrative databases: a perspective on risk adjustment in critical care research. 7 Crit Care 2005;20(1):12-9.

17. Bone R, Balk R, Cerra F, et al. Definitions for sepsis and organ failure and guidelines for the use of innovative therapies in sepsis. The ACCP/SCCM Consensus Conference Committee. American College of Chest Physicians/Society of Critical Care Medicine. Chest 1992;101:1644-55.

18. Kaukonen K-M, Bailey M, Pilcher D, et al. Systemic inflammatory response syndrome criteria in defining severe sepsis. NEFM 2015;372(17):1-10.
19. Sweet D, Marsden J, Ho K, et al. Emergency management of sepsis: the simple stuff saves lives. B C Med $\mathcal{F}$ 2012;54(4):176-82.

20. Fan J, Upadhye S, Worster A. Understanding receiver operating characteristic (ROC) curves. Can 7 Emerg Med 2006;8(1):19-20.

21. Wei LA, Fearing MA, Sternberg EJ, et al. The confusion assessment method: a systematic review of current usage. $7 \mathrm{Am}$ Geriatr Soc 2008;56(5):823-30.

22. Xu M, Tam B, Thabane L, et al. A protocol for developing early warning score models from vital signs data in hospitals using ensembles of decision trees. BM7 Open 2015;5(9): e008699.

23. Dellinger RP, Levy MM, Rhodes A, et al. Surviving sepsis campaign: international guidelines for management of severe sepsis and septic shock, 2012. Intensive Care Med 2013;39(2):165-228.

24. Romero-Brufau S, Huddleston JM, Escobar GJ, et al. Why the C-statistic is not informative to evaluate early warning scores and what metrics to use. Crit Care 2015;19(1):285.

25. Singer M, Deutschman CS, Seymour CW, et al. The third international consensus definitions for sepsis and septic shock (Sepsis-3). FAMA 2016;315(8):801-10.

26. di Martino P, Leoli F, Cinotti F, et al. Improving vital sign documentation at triage: an emergency department quality improvement project. $\mathcal{F}$ Patient Saf 2011;7(1):26-9. 